\title{
Primary Sjögren's syndrome presenting as a case of sarcoidosis and a suspected pancreatic tumour
}

\author{
P P Koopmans, C Bodeutsch, P C M de Wilde, A M Th Boerbooms
}

\begin{abstract}
A 45 year old man, previously diagnosed as having sarcoid, presented with signs and symptoms of a pancreatic malignancy. An explorative laparotomy, however, showed only chronic pancreatitis. He was found to have a raised erythrocyte sedimentation rate, normocytic normochromic anaemia, renal insufficiency, hypergammaglobulinaemia, and a strongly positive rheumatoid factor and antinuclear antibody titre. Bilateral hilar lymph node enlargement was noted on chest $x$ ray. Subsequently, the patient complained of xerostomia and keratoconjunctivitis sicca. Large lymphocytic infiltrates and a shift in the relative number of IgA bearing plasma cells in favour of IgG and IgM bearing plasma cells were seen in tissue obtained by sublabial salivary gland biopsy. A transbronchial lung biopsy and review of the biopsies of the pancreas, the lung, liver, and a lymph node all failed to show granulomatous disease. These findings strongly suggested a diagnosis of Sjögren's syndrome instead of sarcoidosis. This case shows the difficulty sometimes encountered in differentiating between sarcoid and systemic Sjögren's syndrome, and the value of a sublabial salivary gland biopsy.
\end{abstract}

Primary Siögren s syndrome is a chronic inflammatory autoimmune disorder, which may present as the sicca complex only, but may also affect many organs. Sarcoidosis can mimic the clinical symptoms of Sjögren's syndrome and differential diagnosis between these disorders clinically and histologically may be difficult. ${ }^{1}$ Recently, Melsom et al reported a patient presenting with clinical and histological features of Sjögren's syndrome, who seemed to have sarcoidosis. $^{2}$

We present a patient with sarcoidosis, who underwent an exploratory laparotomy for a suspected pancreatic malignancy. Microscopic examination of biopsy specimens of the lung, liver, pancreas, and sublabial salivary gland showed no granuloma formation. The findings in the sublabial salivary gland strongly supported a diagnosis of Sjögren's syndrome.

\section{Case report}

In July 1986 a 45 year old man was referred to the department of general internal medicine by the department of surgery. He had undergone a diagnostic laparatomy because of a suspected pancreatic malignancy. An enlargement of the pancreatic head was found. Microscopic examination of the pancreas showed only extensive fibrosis and a diffuse mononuciear infiltrate, compatible with a diagnosis of chronic pancreatitis. There were no signs of a malignancy in the pancreas or the associated lymph node.

The patient complained of extreme tiredness, a dry mouth, and dysphagia and difficulty in chewing. The submandibulary salivary glands seemed to be enlarged, and six months previously he had consulted an ophthalmologist for dry eyes. There was no arthralgia, anorexia, or weight loss. He had had Raynaud's phenomenon

One year previously he had attended his local hospital because of tiredness. An $x$ ray of the chest had shown bilateral hilar lymph node enlargement and as sarcoidosis was suspected a transbronchial lung biopsy had been performed. Microscopic examination of these biopsy specimens had shown epitheloid cells and a few granulomatous structures. Therefore it was concluded that the patient had sarcoidosis. A few months later he again attended his local hospital because of pain in the right upper abdominal quadrant. Biochemical examination showed raised values for alkaline phosphatase $390 \mathrm{U} / 1$ (normal <125), $\gamma$-glutamyltransferase $519 \mathrm{U} / 1$ (normal <30), S-alanine aminotransferase (91 U/l) (normal <25), and S-aspartate aminotransferase $262 \mathrm{U} / \mathrm{l}$ (normal $<25$ ). A liver biopsy specimen showed small infiltrates of granulocytes and lymphocytes but no evidence of granulomatous disease. An endoscopic retrograde cholangiopancreatography was performed, showing narrowing of the pancreatic and the common bile duct, raising suspicions of a tumour of the pancreas. Computed tomography showed an enlarged pancreatic head. At this point the patient was referred for explorative laparotomy.

Physical examination at the department of general internal medicine showed a patient who looked anaemic with slightly enlarged, tender submandibulary glands, and a dry oral mucosa; otherwise the findings were unremarkable. There was no hepatomegaly, splenomegaly, or lymph node enlargement.

Laboratory investigations showed raised erythrocyte sedimentation rate (ESR) (112 $\mathrm{mm} / \mathrm{h}$ ), a normochromic, normocytic anaemia with a haemoglobin $106 \mathrm{~g} / \mathrm{l}$ (normal 130-160). The other haematological indices were normal. The gammaglobulins were $25 \mathrm{~g} / 1$ (normal 7-15). Serum immunoelectrophoresis showed a hypergammaglobulinaemia and no paraprotein. No cryoglobulins were found. Serological tests for rheumatoid factor, the antinuclear antibody test, and circulating immune complexes were 


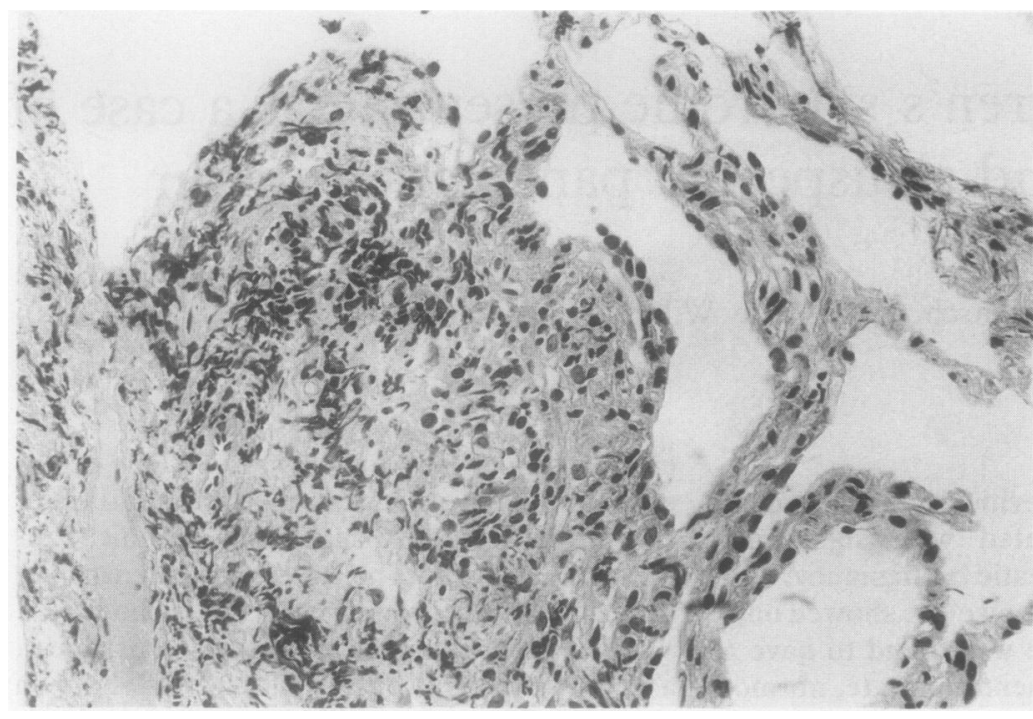

Figure 1: Part of the second lung biopsy specimen with fibrosis and some mononuclear inflammatory cells. No evidence of non-caseating granulomatous process. (Haematoxylin and eosin.)

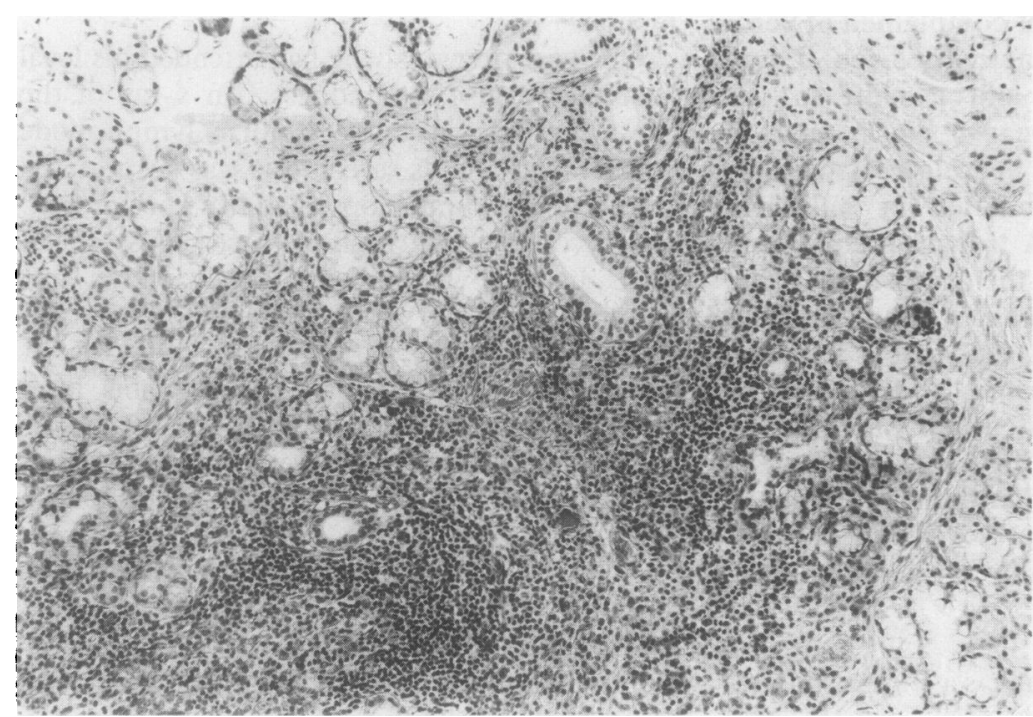

Figure 2: Sublabial salivary gland biopsy specimen with large confluent lymphocytic foci and destruction of parenchyma. (Haematoxylin and eosin.)

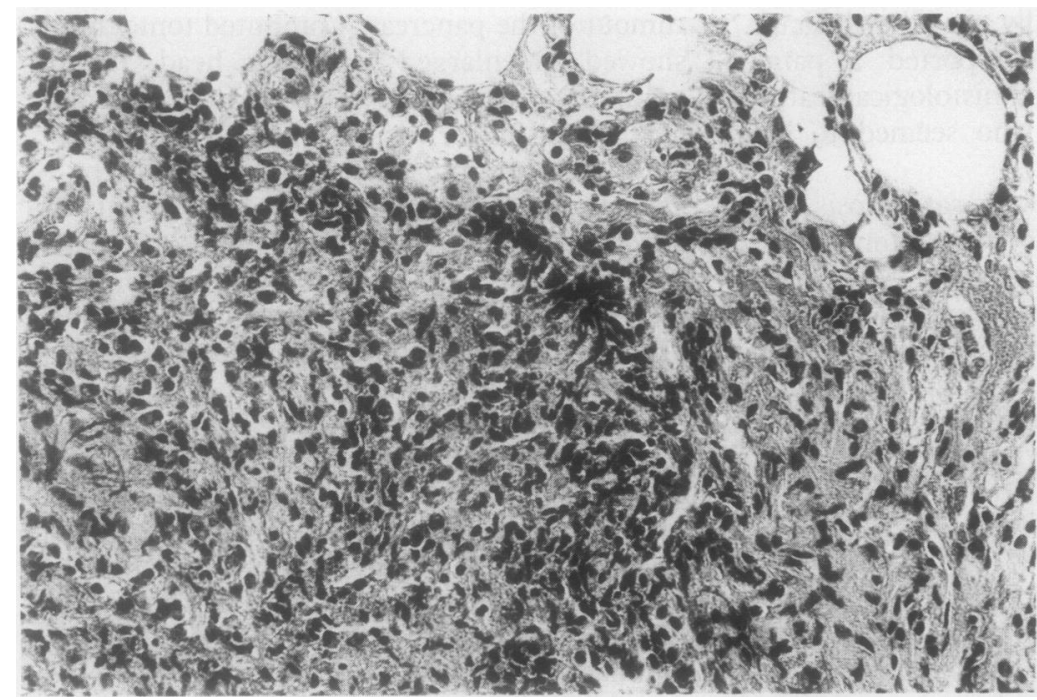

Figure 3: Part of the first lung biopsy specimen with fibrosis and diffuse infiltration with mononuclear inflammatory cells. No evidence of non-caseating granulomatous process. (Haematoxylin and eosin.) strongly positive. SS-A and SS-B were not detected. Serum creatinine was slightly raised (166 $\mu \mathrm{mol} / \mathrm{l})$ (normal 60-100) and there was a proteinuria of $0.82 \mathrm{~g} / \mathrm{l}$. Tests for liver function, serum amylase, and calcium were normal. Angiotensin converting enzyme concentration was increased $20.2 \mathrm{mE} / \mathrm{ml}$ (normal 12-15). A Schirmer test (right $6 \mathrm{~mm}$, left $8 \mathrm{~mm}$ ) showed diminished tear production. Rose bengal staining of the conjunctiva was positive. Routine chest $x$ rays showed diffuse fibrotic lesions and bilateral hilar enlargement, the latter confirmed by tomography. Submandibulary gland sialography was performed, showing diffuse narrowing and widening of the ducts, suggesting chronic inflammation.

As clinically the differential diagnosis lay between sarcoidosis or Sjögren's syndrome, fibreoptic bronchoscopy and a sublabial salivary gland biopsy were carried out. Fibrosis and an infiltration of histiocytes and lymphocytes was found in the lung biopsy specimen (fig 1) but no granulomata, multinucleate giant cells, or epithelioid cells were seen. Microscopy of the sublabial salivary gland biopsy specimen (fig 2) showed large focal lymphocytic infiltrations (focus score 2.5 with confluent foci) and ductal hyperplasia. No granulomata or multinucleate giant cells were found. Immunohistochemical staining showed a polyclonal plasmacytic infiltrate and a shift in the relative number of $\operatorname{IgA}$ bearing plasma cells in favour of IgG and IgM bearing plasma cells. The plasmacytic infiltrate consisted of $40.1 \%$ IgA bearing cells (normal (SD) $91.9(8 \cdot 6) \%, 47 \cdot 1 \%$ IgG bearing cells (normal $3 \cdot 4(4 \cdot 8) \%$ ), and $12 \cdot 8 \%$ IgM bearing plasma cells (normal $4 \cdot 8(4 \cdot 8) \%)^{3}$ Both the histological and immunohistochemical findings in the sublabial salivary gland biopsy specimen were strongly suggestive of Sjögren's syndrome. When revision of the early lung biopsy was performed a non-specific fibrosing inflammatory process was found. Some structures were suggestive of sarcoidosis, but no granulomata, epitheloid cells, or multinucleate giant cells could be shown (fig 3).

\section{Discussion}

Primary Sjögren's syndrome is a chronic inflammatory disorder characterised by lymphoid cell infiltration and destruction of salivary and lachrymal glands, resulting in keratoconjunctivitis sicca and xerostomia. Sarcoidosis may present with keratoconjunctivitis and sialoadenitis resembling Sjögren's syndrome. ${ }^{4}$ In addition, the pulmonary manifestations of Sjögren's syndrome may resemble those of sarcoidosis. ${ }^{56}$ Bilateral hilar lymph node enlargement strongly suggested sarcoidosis in our patient, and this diagnosis was supported by the general symptoms and the raised angiotensin converting enzyme concentration in plasma.

The clinical diagnosis of primary Sjögren's syndrome was supported by the typical ocular and salivary symptoms, the sialoadenitis seen on sialography, and the biochemical indices, including raised ESR, gammaglobulin value, and the positive rheumatoid factor and antinuclear antibody test. ${ }^{7}$ Antibodies to SS-A and SS-B 
were negative, but although often found in Sjögren's syndrome, they are not always present. ${ }^{8}$ Furthermore, the patient had chronic pancreatitis, proteinuria, and raised serum creatinine, which have been reported in primary Sjögren's syndrome. ${ }^{7910}$ Thus as none of these findings is specific a diagnosis on clinical grounds was not possible.

Therefore, a sublabial salivary gland biopsy and a second lung biopsy were carried out to differentiate between sarcoidosis and Siögren's syndrome. Furthermore, when the previous transbronchial lung biopsy specimen was reviewed, no definite granulomata, multinucleate giant cells, or epitheloid cells could be shown, but fibrosis and infiltrations of histiocytes and lymphocytes were present. The first biopsy specimen did, however, show some structures faintly resembling granulomata such as may be found in sarcoidosis.

The histological and immunohistological findings in the sublabial salivary gland biopsy specimen strongly indicated Sjögren's syndrome. ${ }^{3} 1112$ The absence of granulomata was also against a diagnosis of sarcoidosis.

Non-specific infiltrations by mononuclear cells and fibrosis in the biopsy specimens of the liver, lymph node, and pancreas as seen in this case have been often reported in primary Sjögren's syndrome, ${ }^{7}$ and as no granulomata could be shown in these biopsy specimens the diagnosis of primary Sjögren's syndrome was supported indirectly.

In conclusion, this case report shows $(a)$ the severe systemic manifestations, including involvement of the lung, pancreas, and (prob- ably) the kidney, which may occur in primary Sjögren's syndrome; $(b)$ how difficult differential diagnosis from sarcoidosis can be; and (c) that a sublabial salivary gland biopsy may be helpful for the diagnosis.

1 De Wilde P C M, Slootweg P J, Hené R J, Baak J P A, Kater L. Multinucleate giant cells in sublabial salivary gland tissue in Siögren's syndrome.

2 Melsom R D, Speight P M, Ryan J, Perry J D. Sarcoidosis in a patient presenting with clinical and histological features of primary Sjögren's syndrome. Ann Rheum Dis 1988; 47: 166-8.

3 De Wilde P C M, Kater L, Baak J P A, Van Houwelingen J C, Hené R J, Slootweg P J. A new and highly sensitive immunohistological diagnostic criterion for Sjögren's syndrome. Arthritis Rheum (in press).

4 Nessan V J, Jacoway J R. Biopsy of minor salivary gland biopsy in the diagnosis of sarcoidosis. $N$ Engl f Med 1979; 301: $922-4$.

5 Strimlan V C, Rosenow E C, Divertie M B, Harrison E G Jr. Pulmonary manifestations of Sjögren's syndrome. Chest 1976; 70: 354-61

6 Constantopoulos S H, Papadimitriou C S, Moutsopoulos H M. Respiratory manifestations in primary Sjögren's syndrome. Chest 1985; 88: 226-9.

7 Talal N, Moutsopoulos H M, Kassan S S. Sjögren's syndrome. Berlin, Heidelberg: Springer, 1987.

8 Smeenk R, Westgeest T, Swaak T. Antinuclear antibody determination: the present state of diagnostic and clinical determination: the present state of diagnostic and clinical
relevance. Scand $\mathcal{F}$ Rheumatol [S uppl] 1985; 56: S78-92.

9 relevance. Scand F Rheumatol [Suppl] 1985; 56: S78-92. Montefusco P P, Geiss A C, Bronzo R L, Randall S, Kahn
E, McKinley M J. Sclerosing cholangitis, chronic pan$\mathrm{E}$, McKinley M J. Sclerosing cholangitis, chronic pan-
creatitis, and Sjögren's syndrome: a syndrome complex. Am f Surg 1984; 147: 822-6.

10 Versapuech J M, Labayle D, Grange D, Fischer D, Kemeny $F$, D'Hubert E. Cholangite sclerosante, pancreatite chronique et syndrome de Siögren. Ann Med Interme (Paris) 1986; 137: 147-54.

11 Lane H C, Callihan T R, Jaffe E S, Fauci A S, Moutsopoulos $H$ M. Presence of intra-cytoplasmic IgG in the lymphocytic infiltrates of the minor salivary glands of patients with primary Siögren's syndrome. Clin Exp Rheumatol 1983; 1: 237-9.

12 Greenspan J S, Daniels T E, Talal N, Sylvester R A. The histopathology of Siögren's syndrome in labial salivary histopathology of Siögren's syndrome in labial salivary gland biopsi 